\title{
Study On Technical And Economic Limit Of Layer-Recombination And Well Pattern Adjustment
}

\author{
Qingjie Gu*, Daqing Oilfield Company Ltd., Daqing, China
}

\begin{abstract}
Three types of displacement mode coexist in NS Development Area at present, including water flooding, polymer flooding, alkaline surfactant polymer flooding. The well patterns and the injection-production relationship is complex, which leads to many difficulties on the adjustment of development plan. Combining with reservoir characteristics and well pattern deployment, this study investigates the limit of exploitable reserve and the economic limit of effective thickness of single new drilled well under the different crude oil price. Through numerical simulation, the limits of injector-producer spacing, permeability differential and maximum production well segment span were obtained. At the same time, the water flooding and the chemical flooding well patterns were considered coordinately, and the technical policy limits were summarized. The results of the study can help the well pattern adjustment for both the water flooding and the chemical flooding, and also help to lay the foundation for the long term development.
\end{abstract}

\section{Introduction}

The NS Development Area has experienced a course of continuous research and practice since it was put into production. With a very good development effect, it also led to many problems, such as multiple well patterns and layer systems, and the injection-production relationship is complex, the existing development adjustment methods can not satisfy the need of ultra-high water cut oilfield. The technical and economic limits in the field of the recombination layer system and optimize well pattern were obtained by using numerical simulation with economic assessment.

\section{Limit of Recoverable Resources}

The principle of economic efficiency should be adopted in the well pattern adjustment. Recoverable resource of single well is the material base limit for determining the scale of infill well. According to the material balance principle, considering the parameters such as drilling, capital cost, operation cost, tax and internal rate of return (IRR), the lower limit of recoverable resource is estimated with the following equation,

$$
N_{R_{\text {min }}} \geq \frac{\frac{n a(1+a)^{n}}{(1+a)^{n-1}-1+a}\left(S_{Z}+S_{J}\right)}{J(1+Y)-C_{d}-C_{S}}
$$

where, $N_{R \min }$ is the lower limit of recoverable resource of single well; $S_{z}$ is the drilling cost per well; $J$ is crude oil price; $S_{J}$ is the capital cost per well; $C_{S}$ is the oil tax; $C_{d}$ is the oil cost; $n$ is the economic life; $a$ is the rate of discount; $Y$ is internal rate of return.

As shown in Table 1, with the increase of single well investment, the recoverable resource of single well also increases. When the internal rate of return (IRR) is set to be $12 \%$, single well investment costs is 2.4

Copyright (C) the author(s). This work is licensed under a Creative Commons Attribution 4.0 International License.

DOI: $10.14800 /$ IOGR.1145

Received December 12, 2019; revised March 2, 2020; accepted April 10, 2020.

*Corresponding author: guqingjie1218@163.com 
million RMB, and crude oil prices is $\$ 50 /$ barrel, the lower limit of exploitable reserves of single well is estimated to be $2669 \mathrm{t}$.

Table 1-The limit of recoverable resources under different single well investment.

\begin{tabular}{|c|c|c|c|}
\hline \multirow{2}{*}{$\begin{array}{l}\text { Crude oil price } \\
\text { (\$/ barrel) }\end{array}$} & \multicolumn{3}{|c|}{ Limit of recoverable resources $(t)$} \\
\hline & $\begin{array}{c}\text { Single well investment is } \\
2.0 \text { million RMB }\end{array}$ & $\begin{array}{c}\text { Single well investment is } \\
2.2 \text { million RMB }\end{array}$ & $\begin{array}{c}\text { Single well investment is } \\
2.4 \text { million RMB }\end{array}$ \\
\hline 50 & 2218 & 2440 & 2669 \\
\hline 60 & 1638 & 1802 & 1971 \\
\hline 70 & 1298 & 1427 & 1561 \\
\hline 80 & 1075 & 1182 & 1293 \\
\hline 90 & 917 & 1009 & 1103 \\
\hline
\end{tabular}

\section{Limit of Effective Thickness-Water Flooding}

Recoverable resources can be calculated as control in-place resources multiplying recovery. Control resources is defined as the control area multiplies by porosity and oil saturation. So the lower limit of effective thickness can be calculated as Eq. 2 and the results are shown in Table 2.

$$
h=\frac{N_{R_{\min }}}{\pi r^{2} \phi S_{o}\left(E_{R}-R\right)},
$$

where, $h$ is the lower limit of effective thickness; $r$ is the well control radius, which equal to half of the well spacing; $\phi$ is the porosity; $S_{\mathrm{o}}$ is the oil saturation; $R$ is the recovery percent; $E_{\mathrm{R}}$ is recovery.

Table 2-The limit of effective thickness under different well spacing.

\begin{tabular}{|c|c|cccccc|}
\hline $\begin{array}{c}\text { Crude oil price } \\
(\$ / \text { barrel })\end{array}$ & $\begin{array}{c}\text { Limit of recoverable } \\
\text { resources }(\mathrm{t})\end{array}$ & \multicolumn{5}{|c|}{ Lower limit of effective thickness under different well spacing $(\mathrm{m})$} \\
\hline 50 & 2669 & 25.2 & 17.5 & 12.9 & 9.9 & 7.8 & 6.3 \\
60 & 1971 & 18.6 & 12.9 & 9.5 & 7.3 & 5.7 & 4.7 \\
70 & 1561 & 14.8 & 10.2 & 7.5 & 5.8 & 4.6 & 3.7 \\
80 & 1293 & 12.2 & 8.5 & 6.2 & 4.8 & 3.8 & 3.1 \\
90 & 1103 & 10.4 & 7.2 & 5.3 & 4.1 & 3.2 & 2.6 \\
\hline
\end{tabular}

\section{Limit of Effective Thickness-chemical Flooding of Class III Reservoirs}

Two scenarios were carried out, 1) with new drilling wells; 2) with using existing water flooding wells to save drilling investment, but additional cost was added to the investment for polymer flooding project, such as chemical cost and extra capital. The lower limit of effective thickness under different crude oil price for alkaline surfactant polymer flooding was estimated and shown in Figure 1. 


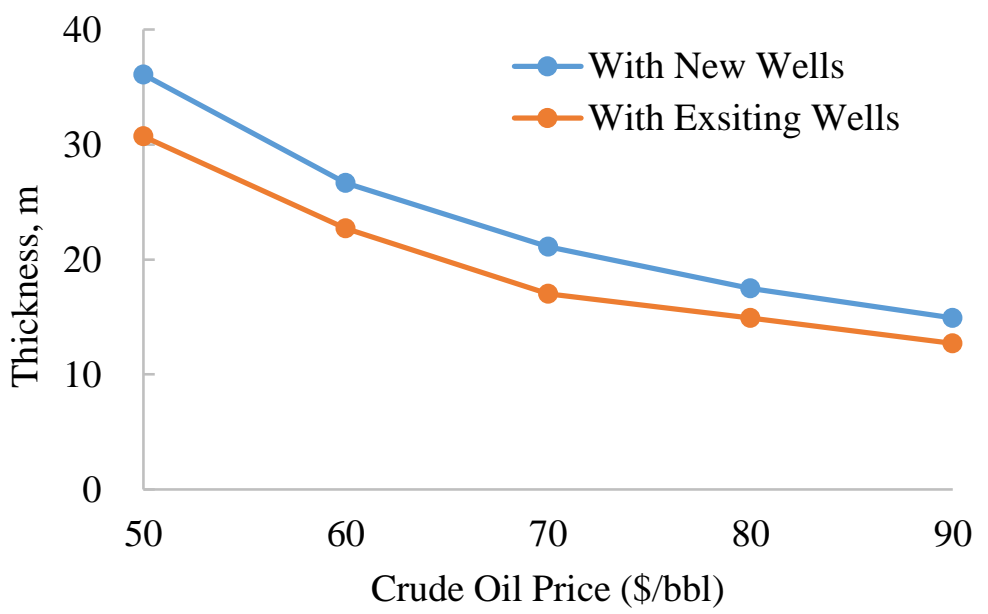

Figure 1-Limit of effective thickness in alkaline surfactant polymer flooding of class III reservoir.

\section{Limit of Injector-producer Spacing}

The recovery speed was estimated and compared with increasing well spacing between injectors and producers. The smaller the well spacing is, the faster to reach the maximum recovery (Figure 2).

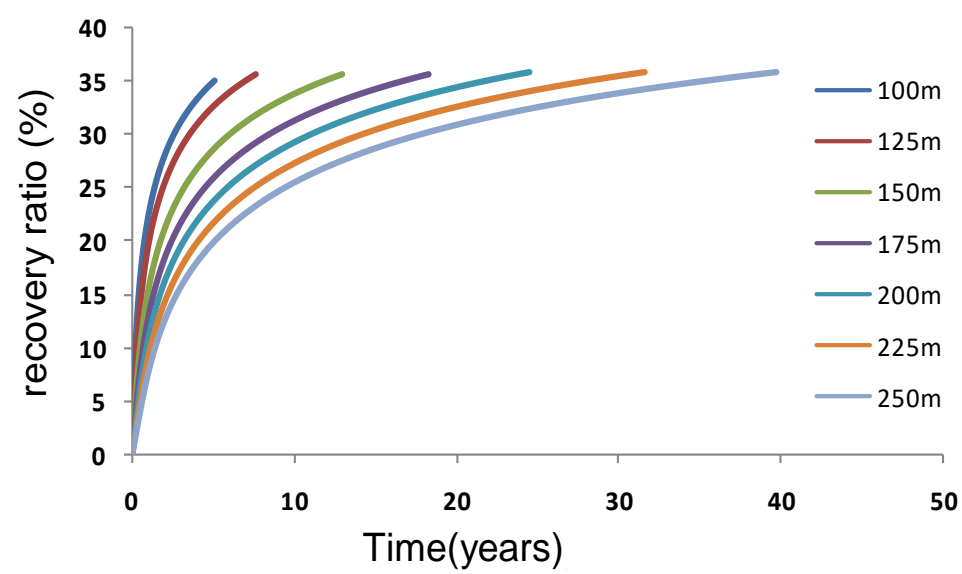

Figure 2-Relation curve between recovery ratio and time with different well spacing.

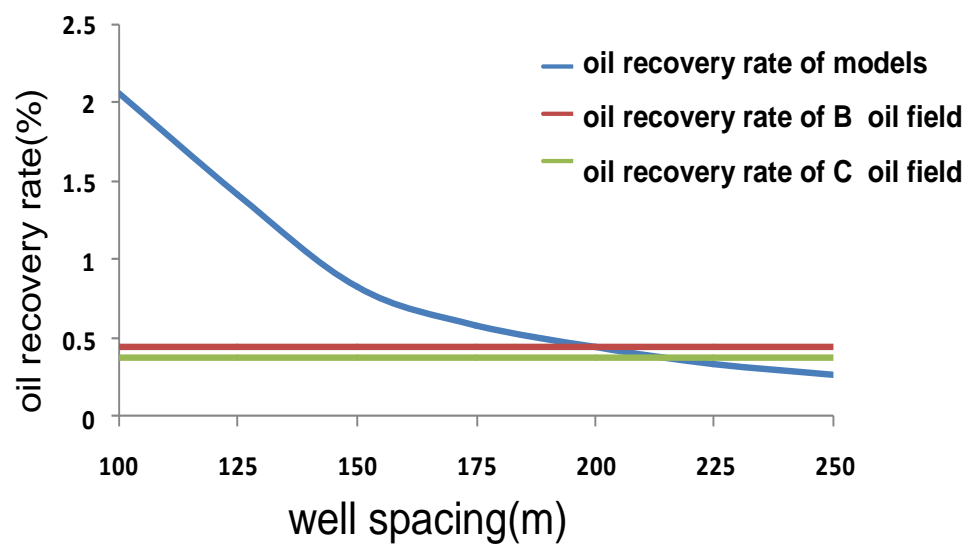

Figure 3-Relation curve between well spacing and oil production rate.

With the increase of well spacing, the oil production rate decreases theoretically (blue curve in Figure 3). At present, the oil production rate of B oilfield is $0.45 \%$ (red curve in Figure 3 ), and that of $C$ oilfield is 
$0.38 \%$ (green curve in Figure 3), intersecting theoretical curve at $200 \mathrm{~m}$ and $220 \mathrm{~m}$, respectively. So the reasonable well spacings were estimated to be $200 \mathrm{~m}$ for B oilfield, and $220 \mathrm{~m}$ for C oilfield. Similarly, the theoretical models were established for Saertu, Putaohua, Gaotaizi layers, respectively. As a result, their reasonable well spacing is $200 \mathrm{~m}, 225 \mathrm{~m}$ and $175 \mathrm{~m}$, respectively.

\section{Limit of Permeability Ratio}

By means of numerical simulation, models for different permeability ratio levels $(1,1.5,2,2.5,3,3.5,4$, $4.5,5,6,8,10$ respectively) were designed. Comparing the development indexes under different permeability ratio by setting the same mining methods and conditions such as the well pattern, the production intensity and the production pressure, conclusions can be drawn. With the increase of permeability ratio, the recovery rate decreases. As the permeability ratio is greater than 4 , the recovery rate decreases rapidly and the development effect is poor. As a result, the upper limit of permeability ratio is estimated to be 4, as shown in Figure 4.

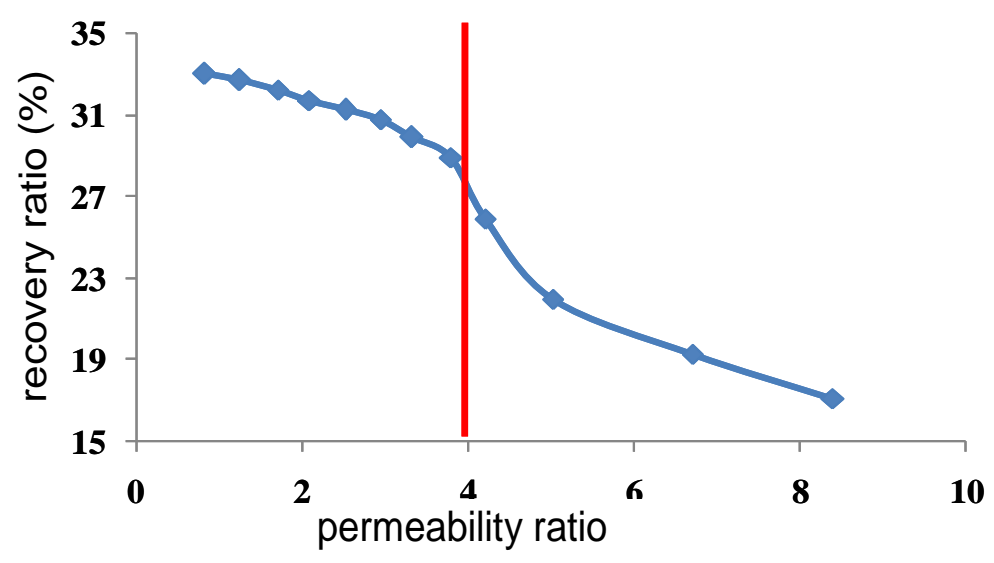

Figure 4-Relation curve between recovery and permeability ratio.

\section{Limit of Production Well Spacing}

By means of numerical simulation, three theoretical models were established and compared (Figure 5). Middle is interlayer, the upper part is layer 2 and the lower part is layer 1, the reservoir thickness is designed as $10 \mathrm{~m}$, the permeability is designed for an average of $350 \mathrm{md}$, porosity is 0.2773 . By controlling the thickness of the interlayer, the development effects under different production wells spacing were simulated. 11 comparative schemes were designed to compare the development effect, including the production wells spacing of $10 \mathrm{~m}, 40 \mathrm{~m}, 70 \mathrm{~m}, 100 \mathrm{~m}, 130 \mathrm{~m}, 160 \mathrm{~m}, 190 \mathrm{~m}, 220 \mathrm{~m}, 250 \mathrm{~m}, 280 \mathrm{~m}, 300 \mathrm{~m}$. With the increase of spacing, the recovery of all the wells decreases gradually, because the recovery of the layer 1 is gradually reduced, and that of layer 2 increases gradually. When the production well spacing is greater than $100 \mathrm{~m}$, the recovery efficiency decreases rapidly and the development effect is poor. So the reasonable production well spacing is less than $100 \mathrm{~m}$. 


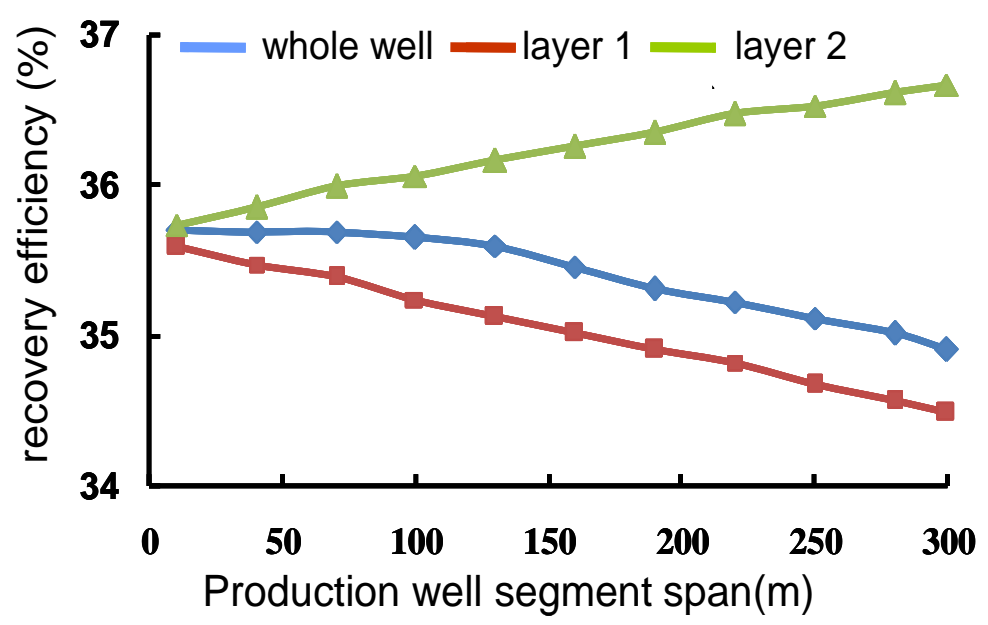

Figure 5-Relation curve between recovery efficiency and production well span.

\section{Conclusions}

When the oilfield enters into the ultra-high water cut stage, more and more development problems will appear. The layer-recombination and well pattern adjustment should hold the principle of economic efficiency. Reuse the existing injectors will reduce the development investment in a large scale. Some guidelines for adjustment plan were estimated and summarized as follows.

- when the crude oil price is 50 dollars/barrel, the lower limit of effective thickness is $12.9 \mathrm{~m}$ with 175 m well spacing;

- when the crude oil price is 70 dollars/barrel, the limit of effective thickness in alkaline surfactant polymer flooding of class III reservoirs is $17.0 \mathrm{~m}$ under the condition of using existing water flooding wells;

- The reasonable well spacing of injector/producer for Saertu, Putaohua, Gaotaizi layers respectively are $200 \mathrm{~m}, 225 \mathrm{~m}$ and $175 \mathrm{~m}$.

- The upper limit of permeability ratio is 4 .

- The reasonable production well spacing is less than $100 \mathrm{~m}$.

To improve the recovery efficiency as much as possible, the above technical and economic limits should be followed when compiling the adjustment plan.

\section{Conflicts of Interest}

The author(s) declare that they have no conflicting interests.

\section{References}

Hu, G. 2012. Study on Limitation of Production Well Segment Span in Multi-Layer Reservoirs. Xinjiang Petroleum Geology 33: 72-78.

$\mathrm{Ju}, \mathrm{H}$. 2008. Study on Rational Well Density and Rational Well Spacing in TX Oilfield. Inner Mongolia Petrochemical Industry 16: 78-83.

Liu, Z., Wang, Q., and Sun, Y. 2014. Study and Application of New Technological Limit for Polymer Flooding in Field Application. Petroleum Geology and Recovery Efficiency 21:22-30.

Wu, J., Zuo, S., and Zhao, X. 2015. Technical and Economic Boundaries on Formation and Well Pattern Adjustment in Lazhong Block. Petroleum Geology and Recovery Efficiency 22:113-118.

Yang, X. 2006. Determination of Rational Well Spacing in Low Permeability Sandstone Reservoir by Dynamic Analysis. Special Oil \& Gas Reservoirs 13: 64-70.

Qingjie Gu is a senior engineer of Daqing Oilfield Company. Dr. Gu specializes in enhance oil recovery and economic analysis. 